\title{
A exteriorização da memória pessoal em Nazareth Pacheco
}

\author{
The Exteriorization of Personal Memory in \\ Nazareth Pacheco
}

\section{La exteriorización de la memoria personal en Nazareth Pacheco}

Hiáscara Alves Pereira Jardim ${ }^{1}$

http://dx.doi.org/10.22409/poiesis.1830.33-54

\begin{abstract}
RESUMO: Este artigo tem como finalidade discutir a relação entre a memória pessoal e a criação artística tendo como base a produção de Nazareth Pacheco. Nesse sentido, o presente artigo aborda o tema da autobiografia evidente em alguns dos objetos artísticos produzidos pela artista nos anos 1990. Analisamos algumas de suas obras de arte em que a memória pessoal é exteriorizada nos elementos visuais que as compõem. Para tanto, adotou-se um corpus teórico diversificado do campo da arte e da psicanálise.
\end{abstract}

PALAVRAS-CHAVE: Nazareth Pacheco; autobiografia; memória; arte contemporânea

\footnotetext{
1 Hiáscara Alves Pereira Jardim é Mestre em Artes, na linha de pesquisa Teoria e Crítica de Arte, pela Universidade Federal do Espírito Santo (2012). Professora de Arte do Instituto Federal do Espírito Santo, Campus Ibatiba. Membro do Grupo de Pesquisa em Diversidade e Gênero - Divergen - CNPq/Capes.

E-mail: hiascara. alves@gmail.com
} 


\begin{abstract}
This article aims to discuss the relationship between personal memory and artistic creation based on the production of Nazareth Pacheco. In this sense, the present article approaches the subject of autobiography evident in some of the artistic objects produced by the artist in the 1990s. We analyze some of her works of art in which personal memory is externalized in the visual elements that compose them. In order to do so, we adopted a diverse theoretical corpus of the field of art and psychoanalysis.
\end{abstract}

KEYWORDS: Nazareth Pacheco; autobiography; memory; contemporary art

RESUMEN: Este artículo tiene como finalidad discutir la relación entre la memoria personal y la creación artística teniendo como base la producción de $\mathrm{Na}$ zareth Pacheco. En este sentido, el presente artículo aborda el tema de la autobiografía evidente en algunos de los objetos artísticos producidos por la artista, en los años 1990. Analizamos algunas de sus obras de arte en las que la memoria personal es exteriorizada en los elementos visuales que las componen. Para ello, se adoptó un corpus teórico diversificado del campo del arte y del psicoanálisis.

PALABRAS CLAVE: Nazareth Pacheco; autobiografía; memoria; arte contemporáneo

Como citar: JARDIM, Hiáscara Alves Pereira. A exteriorização da memória pessoal em Nazareth Pacheco. Poiésis, Niterói, v. 18, n. 30, p. 33-54, dez. 2017.

doi: http://dx.doi.org/10.22409/poiesis.1830.33-54

Poiésis, Niterói, v. 18, n. 30, dez. 2017. 


\section{A exteriorização da memória pessoal em Nazareth Pacheco}

\section{Autobiografia na arte contemporânea}

Este artigo tem como objetivo analisar as referências ao corpo em diferentes momentos da produção da artista Nazareth Pacheco (São Paulo, 1961). ${ }^{2,3}$ Ao longo da pesquisa, foi possível perceber que, no último decênio do século $\mathrm{XX}$, havia um forte interesse entre os jovens artistas brasileiros de explorarem temas referentes à memória (física e psiquíca) por meio da obra, tendência esta observada por teóricos como Kátia Canton (2000) e Tadeu Chiarelli (1997).

No final dos anos 1990, uma parcela significativa da arte brasileira buscava trazer para o campo das artes visuais questões relacionadas ao corpo e à memória do próprio artista.

\footnotetext{
${ }^{2}$ Este artigo é um recorte da dissertação de mestrado intitulada $O$ corpo na poética de Nazareth Pacheco na década de 1990, desenvolvida junto ao Programa de Pós-Graduação em Artes da Universidade Federal do Espírito Santo sob a orientação da Professora Doutora Almerinda da Silva Lopes.

${ }^{3}$ Anteriormente, este artigo foi publicado nos Anais do $26^{\circ}$ Encontro da Associação Nacional de Pesquisadores em Artes Plásticas (ANPAP, Campinas).
} 
Na ocasião do $25^{\circ}$ Panorama da Arte Atual Brasileira, em 1997, o então curador-chefe Tadeu Chiarelli observou que a nova geração de artistas deixava transparecer, na própria constituição do trabalho, suas vivências. Fato que o levou a optar por "agrupá-los a partir de similitudes entre suas diversas experiências, em que o corpo e a memória fossem os elementos aglutinadores, e não as analogias técnicas e/ou de linguagem". (CHIARELLI, 1997, p. 13) De acordo com Chiarelli, havia naquele final de milênio uma série de circunstâncias negativas que levaram muitos artistas a se debruçarem sobre suas histórias pessoais, como também a refletirem sobre a cultura em que estavam inseridos.

Essa tendência, segundo Kátia Canton (2000, p. 52), estaria relacionada à atmosfera negativa que perdurou no final do século XX em decorrência do surgimento da Aids e de outras doenças incuráveis, somado ao crescente "culto ao corpo que permite transformações físicas, às clonagens e aos experimentos genéticos", que acarretaram a perda de nossas certezas e limites. Ao investigar as preocupações estéticas e conceituais da chamada "Geração Noventa", Canton (2000, p. 30), da mesma forma que Chiarelli (1997), verificou que o corpo, a memória e os registros pessoais eram o grande tema dos jovens artistas. Em seu livro Novíssima Arte Brasileira, Canton escreve (2000, p. 52): "A memória corporal torna-se um bem valioso e incomensurável de riquezas afetivas que o artista desnuda e oferece ao espectador com a cumplicidade e a intimidade de quem abre um diário". Nesse sentido, quando o artista opta por expor em uma galeria obras que derivam de sua vida pessoal, o privado torna-se público. No entanto, a obra transcede as fronteiras do particular em busca de um significado que só o espectador poderá lhe dar. A obra não se limita a um único sentido. É daí que resulta sua potência conceitual.

Podemos apontar os autorretratos de Frida Kahlo (1907-1954) entre os precursores dessa tendência autobiográfica no campo das artes plásticas. Em suas pinturas, são visíveis diferentes situações vivenciadas pela artista e alusões ao contexto em que viveu: a revolução mexicana; a cultura pré-colombiana; as sequelas deixadas pelo grave acidente que sofreu; o casamento conturbado com Diego Rivera; os sucessivos abortos naturais que frustraram o desejo de ser mãe. Em seus trabalhos, Kahlo retratava cenas pouco convencionais na arte, naquela época, como imagens do próprio corpo ferido, de fetos e

Poiésis, Niterói, v. 18, n. 30, dez. 2017. 
de órgãos internos à mostra. A artista transformou seu corpo em imagem como tentativa desesperada de exilá-lo da dor, expondo "todo o universo de sua vida privada, sua intimidade, suas alegrias, seus vínculos afetivos, e também, sua vocação políticoideológica". (PROCOPIAK, 2009, p. 52) Frida costumava dizer que pintava a si mesma porque era o assunto que melhor conhecia. Nesse sentido, pincelava sua própria realidade. Ao retratar no plano pictórico, seu corpo mutilado, ensanguentado ou perfurado por espinhos e pregos, símbolos da angústia pessoal, Kahlo transmutou a memória da dor em arte, com um toque onírico.

Louise Bourgeois (1911-2010) é outra artista amplamente conhecida pela base autobiográfica de seu trabalho e ela mesma deixou clara a relação entre sua obra e a história pessoal, em um depoimento publicado pela primeira vez em 1994: "Toda a minha obra dos últimos cinquenta anos, todos os meus temas, foram inspirados na minha infância". (BOURGEOIS, 2000, p. 277) No decorrer de sua trajetória artística, experimentou vários tipos de suportes e métodos: desenhos, pinturas, gravuras, esculturas, objetos e instalações. Durante a infância, passou por situações traumáticas, dentre as quais testemunhou o caso extraconjugal do pai e a doença e consequente morte precoce da mãe.

As produções de Kahlo e Bourgeois refletem momentos que marcaram suas vidas e abrem caminho para as práticas confessionais associadas à arte autobiográfica do final do século XX. Desse modo, este artigo aborda o tema da autobiografia como elemento propulsor da obra de arte, com base em alguns dos objetos artísticos produzidos por Nazareth Pacheco nos anos 1990. Nesse sentido, se analisa algumas de suas obras em que memória pessoal é exteriorizada tornando público o privado, como forma de lidar com a angústia e de levantar questões universais, intrínsecas ao ser humano, como medo e dor. 


\section{Narrativas de si}

As obras de Nazareth Pacheco, sobretudo as produzidas na década de 1990, são constituídas por traços de memória. Em sua arte, a recordação do passado não é movida apenas pelo desejo de dar-Ihe forma narrativa ou de registrar algo vivido, mas também pela vontade de dar-Ihe outro sentido ou significado. Para compor seu universo objetual, a artista utiliza materiais relacionados aos momentos traumáticos que viveu. Trata-se de utensílios médicos, receitas, remédios, agulhas, lâminas de barbear, dentre vários outros.

Pacheco não esconde que nasceu com malformação congênita e, em função desses problemas, teve que passar por várias cirurgias reparadoras e estéticas, desde a infância até os dezoito anos de idade, para alcançar sua atual aparência e conformidade física. Todos esses procedimentos deixaram marcas profundas em sua memória e em sua pele até o momento em que resolveu dar tratamento plástico àquelas lembranças dolorosas. Esse processo, para a artista, não foi angustiante, porque parecia mais com uma lenta viagem que fazia dentro de si, enquanto refletia sobre seu corpo, conforme relata: "Naquele momento [tinha] a impressão de estar descrevendo um processo interior, que era só meu. Ao mesmo tempo era legal. Nada do que fazia ficava pesado, deprimente. Aconteceu justamente o oposto". (PACHECO apud FERNANDES, 2000, p. 3) É justamente nesse contexto que ela produz seu primeiro trabalho considerado pela crítica como autobiográfico, intitulado Objetos Aprisionados (1992).

O referido trabalho consiste em uma série de caixas de madeira, no total quinze, com fundo de chumbo e tampo de vidro. Cada caixa contém algum elemento relacionado ao corpo da artista ou às intervenções cirúrgicas a que foi submetida: fotografias, pinos metálicos, bulas, laudos, prescrições médicas, remédios, moldes em gesso, cabelos, radiografias, dentre outros documentos que são símbolos da tortura que vivenciou. Fechadas e escuras, as caixas de Pacheco remetem a um sarcófago, no qual, ao invés de restos mortais, jazem os fragmentos da memória de um corpo. O chumbo, usado para forrar o

Poiésis, Niterói, v. 18, n. 30, dez. 2017. 
fundo da caixa, "por ser um metal empregado pela medicina como blindagem em exames radiológicos, parece fazer alusão a uma radiografia corporal, ao lado oculto do corpo tornado visível, traduzido pela tampa de vidro transparente". (PEREIRA, 2012, p. 40)

O conteúdo das caixas é similar; a maioria delas contém frascos de medicamentos, bulas, receitas e registros fotográficos. Opta-se por analisar apenas aquelas que se diferenciam materialmente umas das outras. Dentro de uma das caixas, observa-se, além do retrato de Pacheco de costas exibindo sua cabeleira, uma mecha do próprio cabelo cortado (Fig. 1). Em outra, há o molde em gesso de sua arcada dentária que mostra dentes imperfeitos e ainda há uma fotografia que retrata o sorriso da artista, já com a dentição perfeita, após as intervenções cirúrgicas (Fig. 2).

Dentre as caixas pertencentes à série, existe uma que chama bastante a atenção: dentro dela, duas fotografias antigas de Pacheco, ainda bebê, realizadas antes e depois da cirurgia de reparação do lábio leporino; também há um modesto texto que descreve tal anomalia (Fig. 3). Enquanto em uma das imagens a criança dorme profundamente, na outra ela sorri, com os lábios já delineados pelo bisturi. Já no espaço interno de outra caixa, o que se destaca é a foto da radiografia das mãos da artista, acompanhada do laudo médico descrevendo sua deformidade óssea (Fig. 4). Existe também uma caixa que mostra o retrato de Pacheco usando curativo em um dos olhos depois de receber um transplante de córnea.

Os Objetos Aprisionados são perturbadores. Existe algo neles que parece atingir o olhar como uma flecha. Pode ser que tal efeito seja provocado pelo punctum da imagem, termo cunhado por Roland Barthes (1984, p. 66) que designa algo presente na fotografia capaz de afetar o olhar do observador. Mas, que também está relacionado à temporalidade, uma vez que toda fotografia é mórbida, porquanto aponta para algo que já foi e não é mais assim, trazendo à tona toda fragilidade humana. (BARTHES, 1984, p. 141-142) É praticamente impossível ao espectador ficar indiferente diante deles. Presos em caixas de madeira cobertas com vidro, eles parecem penetrar o inconsciente, pois, apesar dos objetos de Nazareth Pacheco narrarem sua história pessoal, a fotografia é mórbida, porquanto aponta 


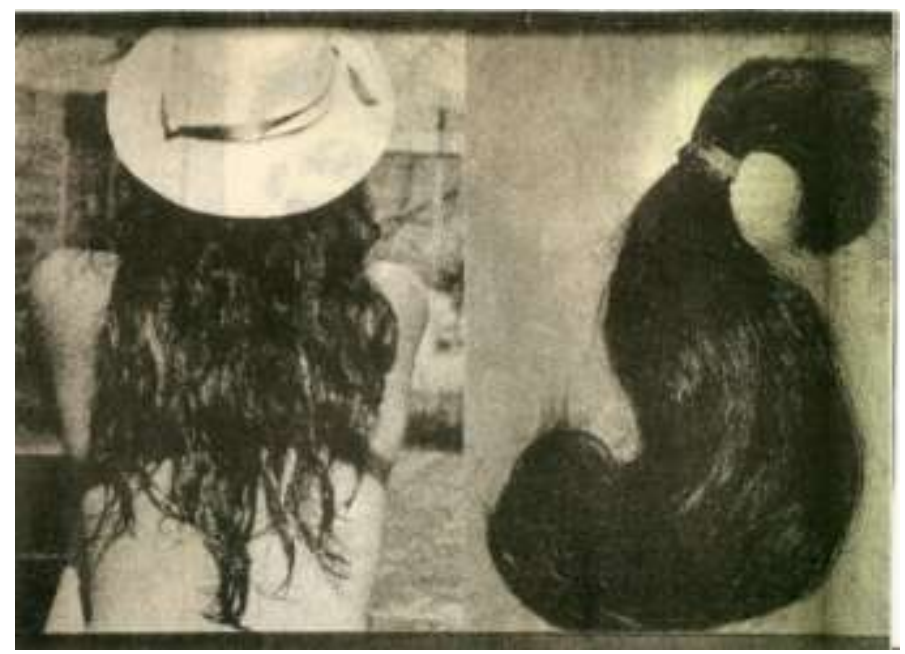

Fig. 1 - Nazareth Pacheco, Sem-título, Série Objetos Aprisionados, 1992-93.

foto, cabelo, elástico e chumbo, $26 \times 36 \mathrm{~cm}$

(Fonte: Jornal da Tarde, São Paulo, 06 out. 1993, s/p)

Poiésis, Niterói, v. 18, n. 30, dez. 2017. 


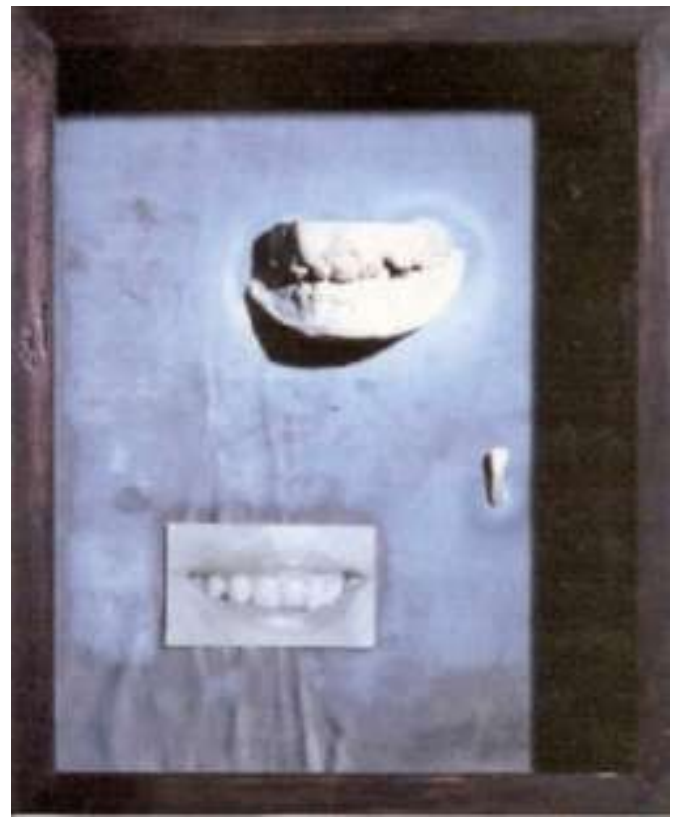

Fig. 2 - Nazareth Pacheco, Sem-título, Série Objetos Aprisionados, 1992-93.

foto, dente e molde de gesso sobre chumbo, $28,5 \times 23,5 \mathrm{~cm}$

(Fonte: Museu de Arte Moderna de São Paulo, SP)

Poiésis, Niterói, v. 18, n. 30, dez. 2017. 


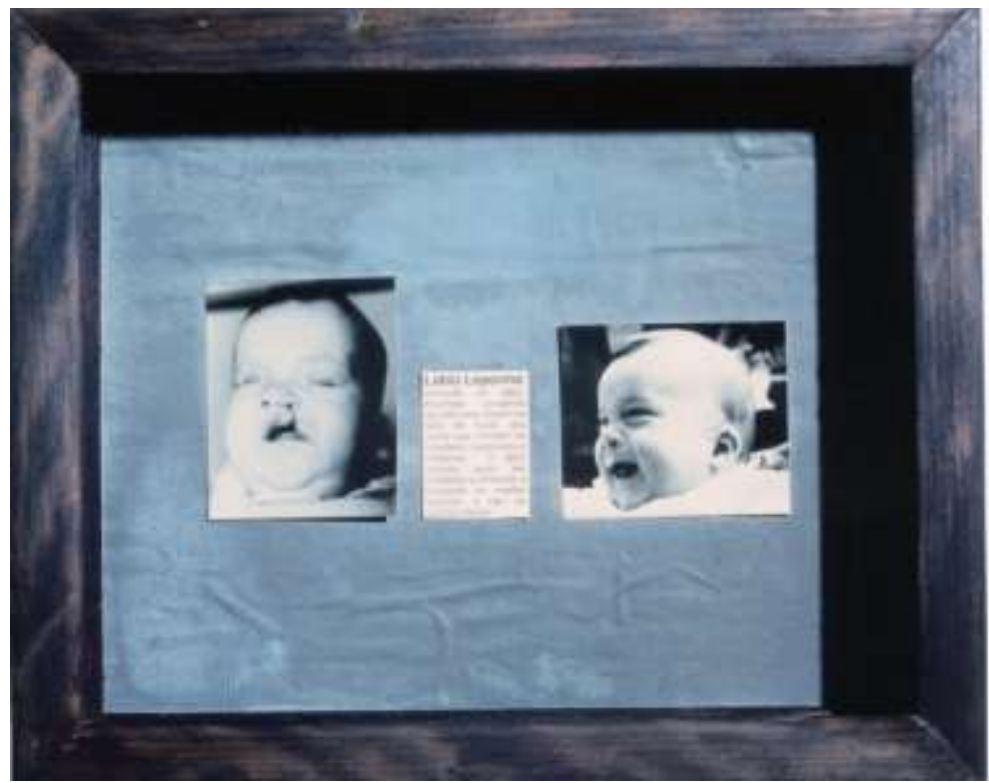

Fig. 3 - Nazareth Pacheco, Sem-título, Série Objetos Aprisionados, 1992-93.

foto de radiografia e relatório sobre chumbo, $44 \times 56 \mathrm{~cm}$

(Foto: Arquivo pessoal da artista)

Poiésis, Niterói, v. 18, n. 30, dez. 2017. 


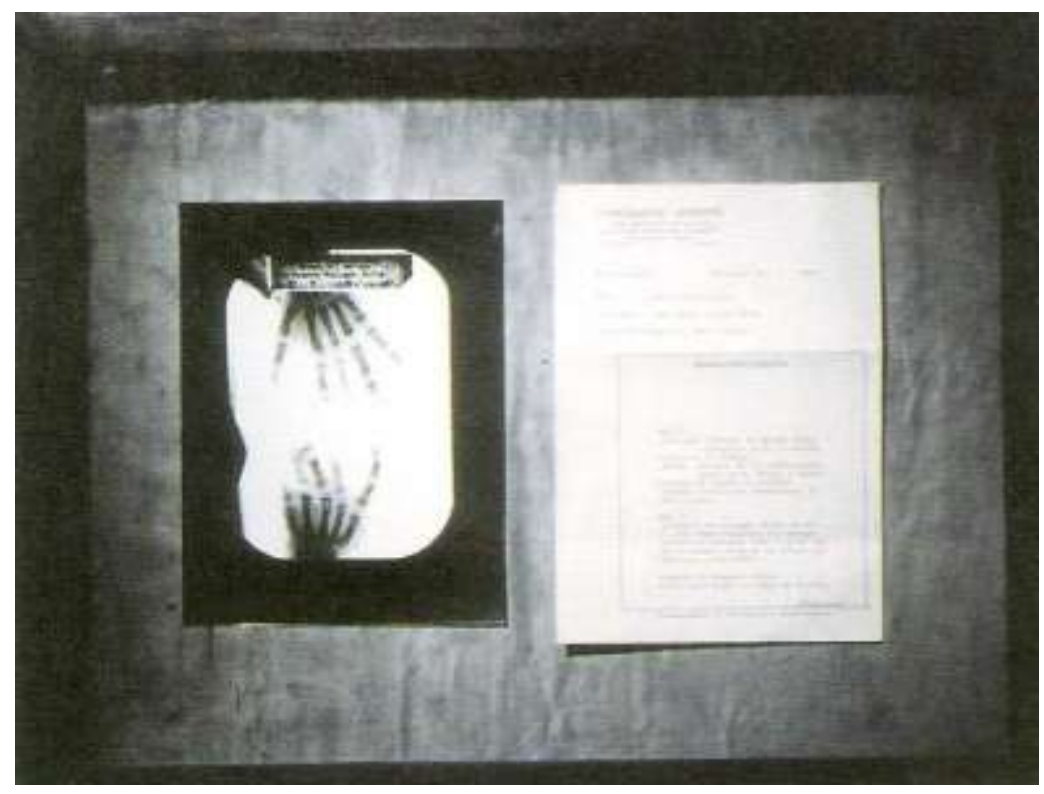

Fig. 4- Nazareth Pacheco, Sem-título, Série Objetos Aprisionados, 1992-93.

foto de radiografia e relatório sobre chumbo, $44 \times 56 \mathrm{~cm}$

(Fonte: MUVI - Museu Virtual de Artes Plásticas, Curitiba, PR)

Poiésis, Niterói, v. 18, n. 30, dez. 2017. 
para algo que já foi e não é mais assim, trazendo à tona toda fragilidade humana. (BARTHES, 1984, p. 141-142) É praticamente impossível ao espectador ficar indiferente diante deles. Presos em caixas de madeira cobertas com vidro, eles parecem penetrar o inconsciente, pois, apesar dos objetos de Nazareth Pacheco narrarem a sua história pessoal,

[...] a obra de arte evoca questões que são universais, que dizem respeito a todos. Sendo assim, o espectador pode ser levado a estabelecer, ou não, relaçoes entre a obra e elementos provenientes de seu próprio repertório individual. As caixas de Nazareth Pacheco seladas como mausoléus, parecem atuar sobre camadas profundas da psique. A impotência diante da dor, a necessidade frequente de exames e intervençōes médicas, o uso de medicamentos, a recorrência ao processo cirúrgico como única opção de cura e o sofrimento físico, nos tocam de alguma maneira, visto que todos nós somos vulneráveis a passar por, pelo menos, algumas situações similares ou podemos nos imaginar em circunstâncias semelhantes. Assim, mesmo que os OjjeosApisionadbssejam uma referência direta à história da artista, as redes de associaçōes podem variar de acordo com a percepção de cada interlocutor. (PEREIRA, 2012, p. 45)

A partir dessa perspectiva, pode-se afirmar que os objetos de Nazareth Pacheco levam a refletir sobre nós mesmos e sobre nosso lugar no mundo. Eles revelam a fragilidade humana e o medo recalcado em todos nós de sentir dor, como também evocam tempos e memórias do passado ou um futuro inevitável pelo qual todo ser vivo irá passar: a morte.

A experiência dolorosa de Nazareth Pacheco serviu como mola propulsora para a criação de outros objetos de arte. O vestido de giletes e cristais Sem título (1997) (Fig. 5) e a série de colares Sem título (1998, Fig. 6) são resultados desse processo que procurou transformar lembranças dolorosas em arte. O primeiro foi exposto no $25^{\circ}$ Panorama da Arte Atual Brasileira (1997), que aconteceu no Museu de Arte Moderna de São Paulo. Já o segundo participou da XXIV Bienal Internacional de São Paulo (1998), mais especificamente do eixo temático Um e Outro - uma subdivisão do segmento de Arte Contemporânea Brasileira: Um/e entre Outro/s -, onde estiveram concentrados os trabalhos mais voltados à questão do corpo e da memória.

Poiésis, Niterói, v. 18, n. 30, dez. 2017. 


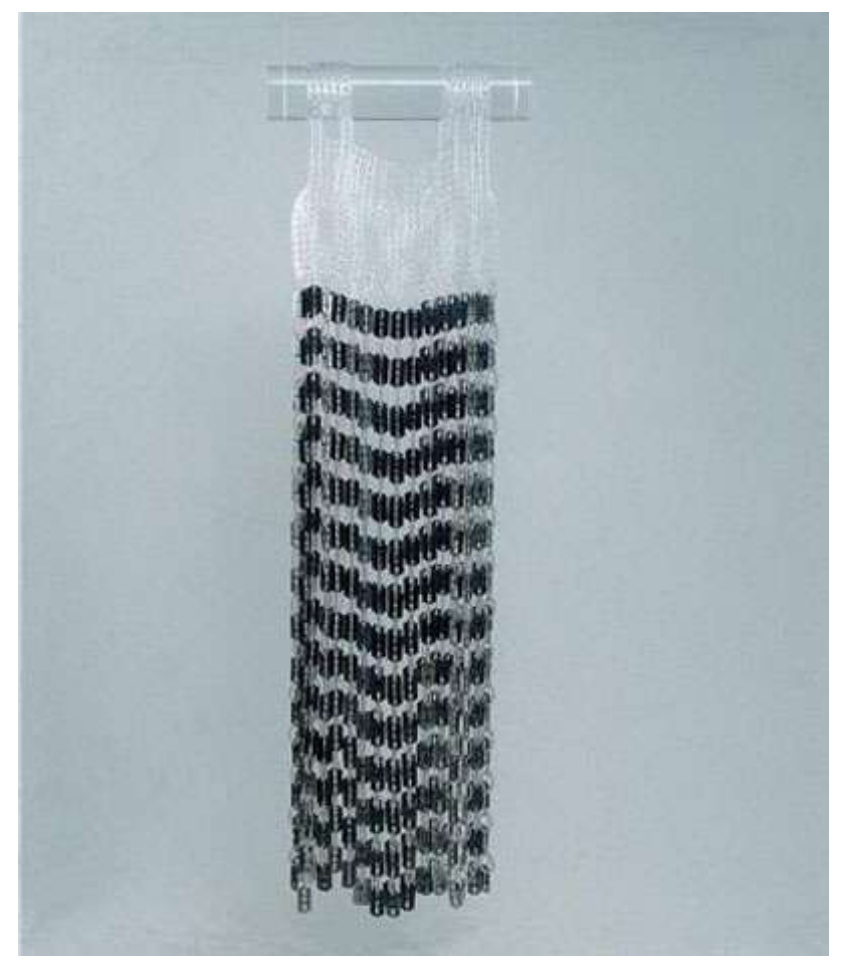

Fig. 5 - Nazareth Pacheco, Sem título, 1997.

cristal, miçanga e gilete, $129 \times 39,5 \times 8 \mathrm{~cm}$

(Fonte: Acervo do Museu de Arte Moderna de São Paulo, SP) 


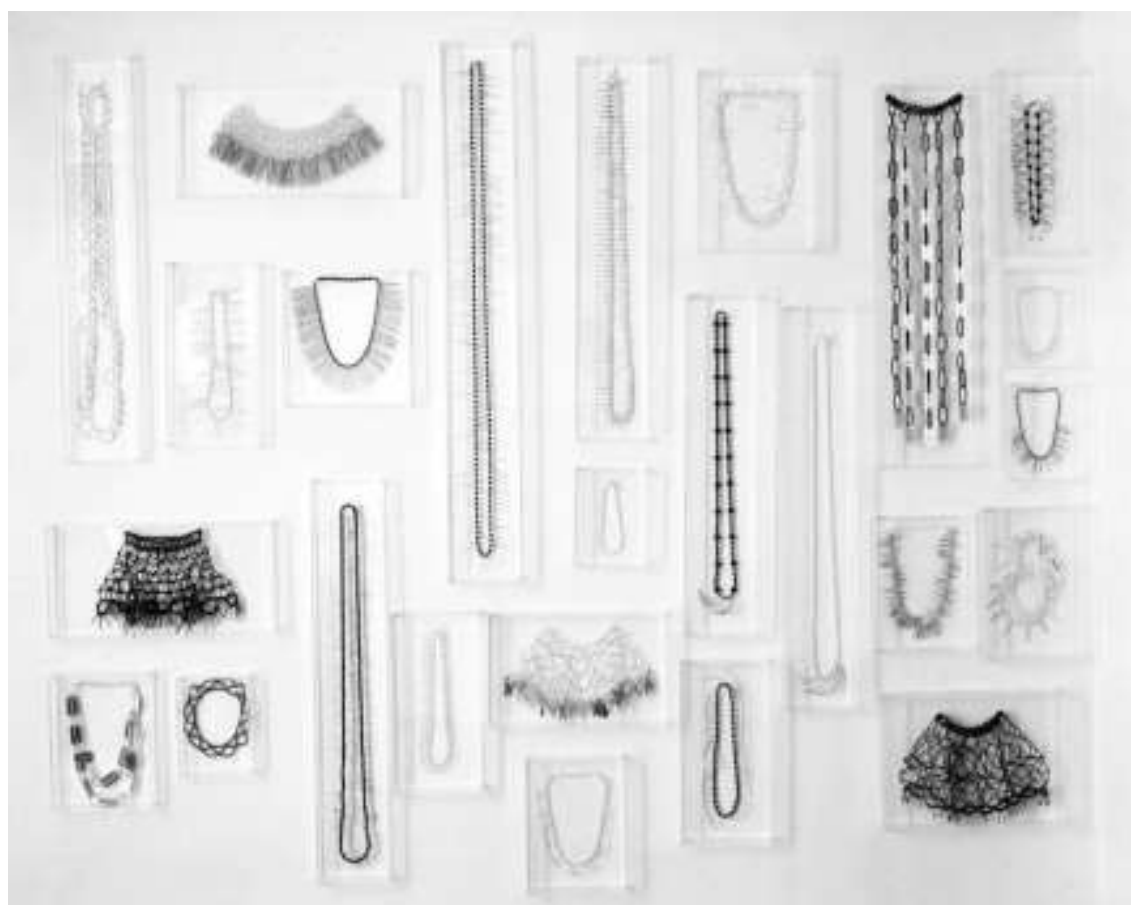

Fig. 6 - Nazareth Pacheco, série de colares, Sem título, 1998.

obra exposta na XXIV Bienal Internacional de São Paulo.

(Fonte: MUVI - Museu Virtual de Artes Plásticas, Curitiba, PR)

Poiésis, Niterói, v. 18, n. 30, dez. 2017. 
O vestido consiste em uma indumentária confeccionada com pequenos cristais e lâminas de barbear unidas por anéis de miçangas. Os colares, por sua vez, foram produzidos em tamanhos e tipos variados. Para criá-los, a artista utilizou instrumentos médicos que, normalmente, são usados para fazer incisões na pele ou furá-la - bisturis, lancetas, aguIhas de sutura. Esses materiais foram combinados com miçangas, cristais e canutilhos. Tudo produzido manualmente. Na XXIV Bienal Internacional, cada adereço apareceu exposto dentro de um estojo de acrílico.

O vestido e os colares de Nazareth Pacheco, à primeira vista, seduzem por sua beleza e brilho. "O reluzir dos cristais ou até mesmo dos metais, quase ofuscavam a ameaça - de cortar ou de ferir - implícita neles". (PEREIRA, 2012, p. 79) Mas, se analisados de perto, revelam-se impiedosos com quem ousar tocá-los. Impossível não sentir certo arrepio diante de tais objetos. Ao contrapor materiais delicados e agressivos, a artista busca despertar sensações ambíguas no espectador: atração e repulsa. De longe, atraem o olhar. De perto, repelem o tato causando certo desconforto e estranhamento.

A artista utiliza o artifício da subversão para inverter a ordem natural de alguns artefatos pertencentes ao universo feminino. Cria uma indumentária que não pode ser vestida. Um colar que não serve de adorno. Itens destinados ao corpo da mulher que são impossíveis de serem usados, porquanto os materiais que os constituem modificam suas funções originais, transformando-os em verdadeiros instrumentos de tortura. Com relação a esses trabalhos, a artista declara o motivo que a levou a criá-los:

Chegou um momento em minha vida em que a questão do modelo ideal de beleza passou a ter um peso grande e foi por meio desta questão que, trabalhando com esses dados, a minha experiência de vida foi "transformada" em arte, mas com uma grande preocupação formal e estética ao realizar os chamados "objetos de arte". (PACHECO, 2001, anline)

Neste sentido, percebe-se que a artista parte de sua experiência individual para abarcar questões mais abrangentes. Em outras palavras, seu trabalho ultrapassa o universo do testemunho autobiográfico para abordar o tema do corpo aprisionado aos padrões prees- 
tabelecidos de beleza. Para tanto, Pacheco constrói objetos - vestido e colares - que simbolizam os suplícios (dietas rigorosas, exercícios físicos em excesso, cirurgias plásticas, lipoaspirações, implantes de silicone etc.) a que muitas mulheres submetem-se para atender aos parâmetros de gosto convencionais. É importante frisar que no caso de Pacheco, as cirurgias corretivas e estéticas foram necessárias para reparar os problemas de natureza congênita. Diferentemente de uma pessoa saudável, que recorre a procedimentos cirúrgicos com o único objetivo de buscar o corpo ideal imposto pela mídia e pela sociedade.

Com relação aos materiais escolhidos para a confecção do vestido e dos colares, Pacheco (2001, online) relata que tem relação com objetos que lhe causavam medo e pânico e que eram utilizados nas cirurgias a que foi submetida: agulhas, lâminas, bisturis. A artista os mescla com cristais, vidrilhos, miçangas e outros materiais sedutores para trabalhar as ideias de beleza e dor. Esses trabalhos são reflexo da atual banalização das cirurgias plásticas que levam um número cada vez maior de mulheres a submeter-se aos procedimentos dolorosos, que envolvem cortes e perfurações, para atingir um padrão inalcançável de beleza. De modo análogo, para vestir a bela indumentária confeccionada pela artista ou um de seus colares é preciso sentir dor. "O perigo que seus objetos representam para quem ousar vesti-los equipara-se ao preço que muitos estão dispostos a pagar para alcançar um acréscimo ou prótese de beleza". (PEREIRA, 2012, p.82) Tais inferências têm como base algumas questões levantadas pela própria artista:

Mas, afinal de contas, o que se faz com um vestido tão lindo, brilhante e cortante? Será que os padrões de beleza impostos pela sociedade ultrapassam o próprio limite da natureza humana? Uma época em que o corpo ideal é o magérrimo, que obriga manequins adolescentes a se submeterem a situações comparáveis às de campos de concentração. Do que vale um corpo perfeito que acaba interferindo e prejudicando a saúde mental? (PACHECO, 2002, p. 46)

Nazareth Pacheco não faz arte panfletária; seus trabalhos são comentários visuais que abordam não apenas sua própria experiência, mas abrem espaço para um debate mais amplo sobre o corpo da mulher na cultura ocidental. O vestido e os colares foram a solu-

Poiésis, Niterói, v. 18, n. 30, dez. 2017. 
ção formal que encontrou para transformar objetos que the causavam medo e dor em arte. Mas, como dito, os mesmos extrapolam a fronteira do singular e caminham em outra direção, ao questionar os padrões de perfeição que aprisionam o corpo contemporâneo.

A contradição entre forma e conteúdo que caracterizou o vestido e os colares também aparece nos trabalhos subsequentes. É o caso da instalação (1999, Fig. 7) exposta na mostra coletiva Transcendência - caixas do ser, realizada na Casa das Rosas, São Paulo. Na ocasião, a artista também apresentou objetos que tinham uma ligação direta com sua história pessoal. Na parede da galeria, ela fixou quatro caixas de luz com imagens ultrassonográficas de fetos com malformação genética, que faziam menção à anomalia que a acometeu quando ainda estava no ventre de sua mãe, causando-Ihe algumas deficiências físicas. Em um dos cantos da sala, Pacheco colocou um pequeno berço de acrílico transparente com suporte de aço, semelhante aos de recém-nascidos usados em hospitais, e sobre o mesmo um cortinado de giletes e miçangas. Ação que transformou o berço, que seria lugar de conforto para o corpo do bebê, em lugar de tortura. O berço parece simbolizar a infância perdida e os sofrimentos vividos por Pacheco desde pequenina, porquanto com apenas dois meses de idade já havia passado por uma cirurgia para corrigir o lábio leporino e por muitos outros procedimentos que vieram logo depois. (PEREIRA, 2012) Ainda compõe a referida instalação, um banco preto de acrílico repleto de agulhas fixadas no assento. As medidas do banco correspondem às do corpo da artista, o que remete de imediato a um ataúde construído no tamanho do falecido. Seu formato e sua cor trazem implícitas as ideias de morte, luto e dor, o que é intensificado pela presença cruel das agulhas.

Para compor essa instalação, Pacheco usou como referência à artista plástica Louise Bourgeois, já citada anteriormente, que descobriu através da escultura uma maneira de lidar com o medo, ou seja, uma maneira de reexperimentá-lo, manipulá-lo, "dar-lhe um caráter físico" para então "destruí-lo". (BOURGEOIS, 2000, p. 227) Pacheco encontrou na 


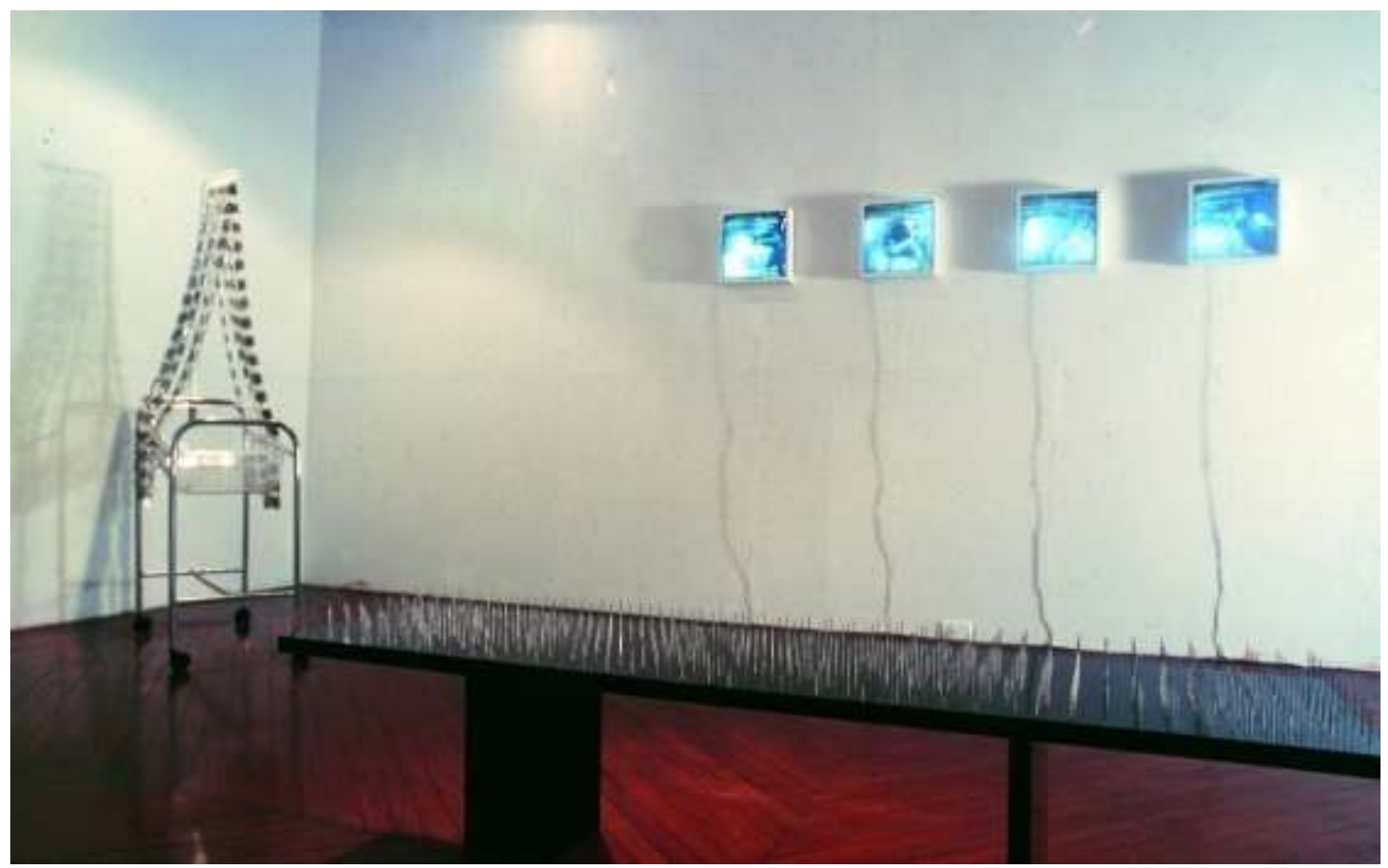

Fig. 7 - Nazareth Pacheco, Sem título, 1999.

instalação

(Foto: Arquivo pessoal da artista)

Poiésis, Niterói, v. 18, n. 30, dez. 2017. 
artista franco-americana um modo de exorcizar seus medos e suas dores, transformandoos em objetos de arte:

A Louise Bourgeois fala disso, de você transformar o medo num objeto para que você possa lidar diretamente com ele [...]. Eu tinha pânico de agulhas. Quando ia ser operada, eu dizia: minha mãe, não dá para cortar essa fase? No fim, eles colocavam aquele cheiro, aquela máscara para eu desmaiar e eu sempre passava mal depois da cirurgia. Mas, pelo menos, eu não sentia esse momento da perfuração, que para mim parecia uma broca de tanto pânico, de tanto medo. (PACHECO apud PEREIRA, 2012, p. 114-118)

A artista brasileira, por sua vez, não costuma esconder a admiração que sente por Bourgeois, falecida em 2010, a quem conheceu pessoalmente em julho de 1999. É importante observar que as duas artistas se diferem bastante plasticamente quanto à utilização de materiais e de métodos usados na construção de suas obras, mas, apesar disso, revelam alguns pontos em comum. "Ambas tiveram a infância marcada por eventos dolorosos e souberam transformar suas experiências em combustível para a arte". (PEREIRA, 2012, p. 97)

Voltando a instalação exposta na Casa das Rosas, as imagens ultrassonográficas, o berço com cortinado de giletes e o banco repleto de agulhas, ao mesmo tempo em que narram a história de Pacheco desde bebê até adulta, demonstram uma tentativa de ressignificar o passado e de "transcender os próprios limites da vida". (SILVA, 2002, p. 307)

Vale lembrar que, exatamente no final século XX, havia certa "atração da arte contemporânea por imagens de dor, deformação e violência", que eram "exibidas como simulacros". (CANTON, 2009, p. 41) Inserida nesse contexto, Pacheco parece ter encontrado o ambiente ideal para reformular seu passado como um modo de compreender a si mesma de maneira mais ampla. Pode ser que as circunstâncias contribuíram para que a memória da dor invocada, naquele momento, em seu processo criativo fosse mais bem filtrada e ganhasse um novo significado através da arte. Nesse caso, o medo e a dor são os elementos-chave da expressão artística. 
$\mathrm{O}$ ato por intermédio do qual o passado recebe ressignificação no presente, segundo Joan Gibbons (2007), recebe o nome de Nachträglichkeit, termo em alemão cunhado por Sigmund Freud que pode ser traduzido como retroatividade. Esse conceito representa um processo psíquico, pelo qual "uma experiência original é reconstituída, retranscrita ou rearranjada em relação às circunstâncias em curso", estabelecendo um novo significado desta para o sujeito. (GIBBONS, 2007, p. 15-16)

No tocante a memória, Gibbons (2007) destaca que não se trata de um local onde são armazenados os dados para depois recuperá-los, mas sim a chave para a compreensão emocional de nós mesmos ou do mundo. Sendo assim, muitas vezes o que foi vivido tem que ser escavado para revelar camadas mais profundas, ou seja, tem que ser processado para ganhar uma resignificação. Nazareth Pacheco introduz agulhas, bisturis, lancetas, dentre outros materiais, em sua produção como uma tentativa de enfrentar, no presente, o medo e a dor que esses objetos Ihe causavam no passado, durante as cirurgias a que era submetida. A arte a permitiu lidar com esses sentimentos, materializá-los, ressignificá-los.

A noção de Nachträglichkeit, de acordo com Gibbons (2007), permite concluir que o reprimido sempre ressurge em um apropriado, no momento em que a revisão e a reconstituição da experiência pode ser revivida. Na arte de Pacheco, o reprimido retorna nos objetos cortantes e perfurantes que compõem o vestido, os colares, o berço, o banco. Todavia, ao mesmo tempo em que a artista recorda e reconstrói o seu passado, ela também tece comentários sobre o presente.

Quando olhados além do aspecto visível, os trabalhos de Pacheco incluem o contexto cultural em que estão inseridos, abordam à questão dos padrões estéticos que aprisionam o corpo e as relações entre beleza e dor. Sabemos que a experiência da dor pode ser física ou psíquica. Todos nós já a experimentamos em algum momento da vida. Nesse sentido, ainda que os objetos da artista tenham relação com os momentos dolorosos que vivenciou no passado, eles transcendem o particular e tocam a dor do espectador. Desse modo, conclui-se que a obra de arte, por mais que seja autobiográfica, não expressa os

Poiésis, Niterói, v. 18, n. 30, dez. 2017. 
sentimentos do artista e sim o sentimento humano. Os objetos de arte criados por Pacheco evocam questões que são universais, que dizem respeito a todos. Assim, mesmo que seus objetos tenham ligação com sua memória pessoal, as redes de associações podem variar de acordo com a percepção de cada observador. A obra não se limita a um sentido único. A radicalidade do trabalho de Pacheco, com suas lâminas e pontas afiadas, demonstra a vulnerabilidade do corpo perecível que somos. Esse corpo que sente dor, sangra, sofre e deseja.

\section{Referências}

BARTHES, Roland. A Câmara Clara: nota sobre a fotografia. Rio de Janeiro: Nova Fronteira, 1984.

BOURGEOIS, Louise; BERNADAC, Marie-Laure; OBRIST; Hans-Ulrich. Louise Bourgeois: destruição do pai, reconstrução do pai. São Paulo: Cosac Naify, 2000.

CANTON, Kátia. Novíssima arte brasileira: um guia de tendências. São Paulo: Iluminuras, 2000.

CANTON, Kátia. Corpo, identidade e erotismo. São Paulo: Martins Fontes, 2009.

CHIARELLI, Tadeu. A experiência do artista como parâmetro. In: CHIARELLI, Tadeu; CINTRÃO, Rejane; CHNAIDERMAM, Miriam. Nazareth Pacheco. São Paulo: D\&Z, 2003.

COCHIARALE, Fernando. Panorama de Arte Atual Brasileira 97. São Paulo: Museu de Arte Moderna de São Paulo, 1997. Catálogo de exposição.

FERNANDES, José Carlos. Colares Colados à pele de Nazareth Pacheco. Gazeta do Povo. São Paulo, 25 jun. 2000.

GIBBONS, Joan. Contemporary Art and Memory: Images of Recollection and Remembrance. New York: I.B. Tauris \& Co Ltd, 2007. 
PEREIRA, Hiáscara Alves. O corpo na poética de Nazareth Pacheco na década de 1990. 2012. 128f. Dissertação (Mestrado em Artes). Programa de Pós-Graduação em Artes, UFES, Espírito Santo, 2012.

PROCOPIAK, Ana Lúcia. Transgressões femininas. São Paulo: Editora Plus, 2009.

SILVA, Nazareth Pacheco. Objetos Sedutores, 2002. 100 f. Dissertação (Mestrado em Artes) - Programa de Pós-Graduação em Artes, Escola de Comunicação e Artes da Universidade de São Paulo, ECA -USP, São Paulo, 2002.

SILVA, Nazareth Pacheco. Entrevista concedida a Tadeu Chiarelli, mar. 2001. Disponível em http://www.muvi.advant.com.br/artistas/n/nazareth_pacheco. htm. Acesso em: 10 abr. 2017. 